\title{
Um país sem vacinas: sem imunidade, com impunidade
}

\section{A country with no vaccines: without immunization, with impunity}

\section{Uno país sin vacunas: sin inmunidad, con impunidad}

\author{
Igor Sacramento ${ }^{1,2, a}$ \\ igor.sacramento@icict.fiocruz.br | https://orcid.org/0000-0003-1509-4778 \\ ${ }^{1}$ Fundação Oswaldo Cruz, Instituto de Comunicação e Informação Científica e Tecnológica em Saúde, Laboratório de \\ Comunicação e Saúde. Rio de Janeiro, RJ, Brasil. \\ 2 Universidade Federal do Rio de Janeiro, Programa de Pós-Graduação em Comunicação e Cultura. Rio de Janeiro, RJ, \\ Brasil. \\ a Doutorado em Comunicação e Cultura pela Universidade Federal do Rio de Janeiro.
}

Palavras-chave: Biopoder; Necropolítica; Covid-19; Pandemia; Políticas públicas.

Keywords: Biopower; Necropolitics; Covid-19; Pandemic; Public policies.

Palabras clave: Biopoder; Necropolítica; Covid-19; Pandemia; Políticas públicas.

A noção de biopoder concebida por Foucault (1978) aponta para o fato de que a vida da população - sua atividade econômica, saúde, estruturas familiares, higiene, nutrição, características demográficas - passou a ser vista como alvo positivo da atividade do Estado (por exemplo, infraestrutura urbana construída, programas de bem-estar social de todos os tipos). Fazer viver é um dos objetivos centrais do biopoder. A manutenção de formas saudáveis ou benéficas de circulação (mercadorias, dinheiro, ar puro) e a supressão de formas prejudiciais (por exemplo, drogas nocivas ou doenças transmissíveis).

Em relação à crise atual da Covid-19, um dos principais objetivos biopolíticos das medidas estatais tem sido, em geral, interromper a circulação prejudicial do vírus, fechando a circulação de seus portadores humanos, ou pelo menos limitando o contato entre as unidades de circulação humana, proibindo o contato entre as famílias, mesmo em espaços públicos ou comuns. Em segundo lugar, o movimento de bens e dinheiro continua necessário, tanto em geral, como especialmente para manter vivos os seres humanos, parcialmente imobilizados. A divisão entre circulações benignas e perigosas de mercadorias não pode ser completa, devido à necessidade de seres humanos no decorrer do transporte e da distribuição. Isso já aponta para uma tensão dentro da lógica biopolítica básica do cultivo da vida humana: para 'fazer viver', em vez de 'deixar morrer', pode ser visto como necessário tornar a forma de vida específica temporariamente menos saudável ou gratificante para alguns grupos. Ser 'feito para viver' ao preço da qualidade de vida talvez seja ilustrado de forma mais pungente pela situação de muitos idosos e enfermos alojados em instituições que agora proíbem as visitas de familiares e amigos. 
No Brasil, em particular, a história das políticas e estratégias de controle da pandemia de Covid-19 é profundamente marcada por negacionismos, omissões, impunidades. Sem contar com um ministro do campo da saúde, o país, com um dos mais robustos e importantes programas de imunização do mundo, amargura uma vacinação lenta, quase estática, enquanto o número de mortes, depois de um ano de pandemia, chega a recordes dos quais ninguém pode se orgulhar. A falsa oposição entre economia e saúde, a insistência no que se chama de "tratamento precoce", baseado em medicamentos já refutados por inúmeras pesquisas científicas (CORRÊA; VILARINHO; BARROSO, 2020), a localização xenofóbica da responsabilidade pela pandemia ("o vírus chinês") (SACRAMENTO; MONARI; CHEN, 2020), a suspeição descabida em relação à eficácia de vacinas (“a vacina chinesa”) (SACRAMENTO, 2020), a recusa em promover medidas sanitárias básicas (isolamento social, testagem em massa, quarentena e lockdown) (CAPONI, 2020), a crença de que se trata apenas de "uma gripezinha", a falta de oxigênio hospitalar, as mortes por asfixia, o número ínfimo de doses de vacina no Brasil, que, nesse ritmo, nas projeções mais otimistas, concluiria a vacinação em 2025, tudo isso faz com que, para nós, brasileiros, a dimensão catastrófica da Covid-19 ainda tenha gravidade, profundidade e alcance desconhecidos.

O conceito de imunidade ganhou um lugar central na interpretação do biopoder apresentada por Roberto Esposito (2017). Na semântica de imunização de Esposito, negação e proteção da vida não se excluem, mas estão intrinsecamente ligadas. Para proteger a vida, os atores políticos devem exercer uma "exclusão inclusiva" de algumas ameaças que negam a vida. Assim, para Esposito, uma importante técnica biopolítica de imunização é a vacinação. Vacinar uma sociedade significa intensificar e fortalecer a vida por meio da intrusão controlada de uma certa dose do patógeno objetável, menor o bastante para não explodir como uma doença desenvolvida no corpo, mas, no entanto, suficiente para evitar novas infecções e prevenir patogenicidade, tanto quanto possível, com uma defesa imunológica fortalecida recentemente. No entanto, a imunização também sempre traz o perigo de desenvolver uma dinâmica prejudicial, expressando-se em medidas mortais, nas quais o poder protetor da vida da imunização se volta radicalmente sobre seu próprio corpo e desmorona em algo como uma 'doença autoimune' ou um 'paroxismo' autoimune, que Esposito vê como tendo sido mais demonstrado no nazismo.

$\mathrm{Na}$ falta de vacinação em massa para proteger a população brasileira contra o patógeno Covid-19, o 'inimigo interno' não pode ser eliminado porque só existe em 'união pessoal' com a população a ser protegida. O distanciamento social e as medidas de higiene deveriam adquirir grande importância, uma vez que a circulação contínua de corpos humanos é simultaneamente perigosa e necessária. No entanto, tais práticas continuamente são rechaçadas, descredibilizadas, diminuídas ou até ridicularizadas pelos nossos representantes no governo federal.

A falta de política de imunização efetiva se soma à garantia de impunidade. Com ou sem panelas sendo batidas, com algum descontentamento crescente, transborda a certeza de impunidade. Os políticos populistas, enquanto populares, gozam de inúmeros benefícios: são os privilegiados desse mesmo sistema, em todas as suas expressões (políticos, empresários, instituições), pois, apesar das denúncias confirmadas sobre crimes de responsabilidade, eles ficam impunes (negação, pactos de silêncio, conluios, compadrio, patrimonialismo, troca de favores) pela manutenção da ordem e da autonomia entre os poderes. Esta foi uma temática recorrente durante um ano de pandemia. Somam-se mortes, famílias enlutadas, perdas irreparáveis, dores, lágrimas, mas ninguém é responsabilizado. Nunca foi tão perverso dizer "vida que segue”. E daí?

Como acrescenta Achile Mbembe (2016, p. 146),

as armas de fogo são implantadas no interesse da destruição máxima das pessoas e da criação de 'mundos de morte', novas e únicas formas de existência social, em que vastas populações estão submetidas a condições de vida que lhes conferem o estatuto de 'mortos-vivos'. 
Ou seja, o termo necropolítica refere-se a "formas contemporâneas que subjugam a vida ao poder da morte (necropolítica) reconfiguram profundamente as relações entre resistência, sacrifício e terror" (p. 146). Discussões sobre as alocações de recursos durante a pandemia Covid-19 no Brasil, que vão desde a recusa de mecanismos respiratórios e de acesso aos leitos de UTI em detrimento dos idosos e das pessoas com deficiência, foram justificadas por uma racionalidade neoliberal associada à necropolítica, literalmente sacrificando vidas, considerando que a contribuição funcional desses grupos, para produção e consumo, não é mais de interesse para o sistema econômico. Além disso, a biopolítica é transmutada ou complementada na abordagem necropolítica de modo a determinar quais corpos valem a pena ser vividos e quais corpos serão excluídos.

Mbembe (2016) observa o direito soberano de matar ressurgindo em sociedades onde a dinâmica do Estado de exceção ou de emergência é perpetuada - conforme Agamben (2004) uma vez afirmou - a partir da construção ficcional de um ou vários grupos considerados inimigos. É possível observar indivíduos que se encontram em condições semelhantes, como, por exemplo, negros, pobres, pessoas com deficiência, idosos, povos indígenas, entre outros. Desta forma, quem deve viver e aqueles que devem morrer são selecionados por esse modelo de Estado.

Da mesma maneira, a existência de mundos de morte onde as pessoas estão em uma condição de morto-vivo é um indicador de necropolítica. No cenário brasileiro, a necropolítica se materializou em face da pandemia Covid-19, de forma amplamente aberta nas declarações e ações de líderes políticos, desconsiderando as mortes causadas pelo novo coronavírus, bem como por meio das mortes causadas pelo não acesso aos sistemas de saúde e pela violação do direito universal à saúde.

Estamos sem vacinas. Somos quase impelidos a comemorar a chegada a conta gotas de uma pinga de vacinas. O que são dois milhões de doses num país de mais 200 milhões de habitantes? Seguimos a vida, os corpos se empilham. Seguimos a vida, a morte se avizinha.

Assim, a questão da saúde no Brasil opera necropoliticamente porque produz condições mortais pela falta de equipamentos, por exemplo, com a escassez ou insuficiência de respiradores e leitos de UTI, funcionando como um elemento fundamental característico de gestão de certas populações, sobrecarregando o serviço público de saúde e tornando-o precário com o objetivo de expor populações vulneráveis à morte ou fazê-las viver em condições extremas para que as fronteiras entre a vida e a morte se tornem muito pequenas. Da mesma forma, é orquestrada uma perspectiva a partir de uma lógica imunológica; por exemplo, da mesma maneira que acontece no caso da imunologia, em que um organismo externo infecta, contamina um corpo saudável e, como resultado, as defesas biológicas passam a reagir combatendo o parasita, procedendo sua eliminação para manter uma boa saúde. Em outras palavras, da mesma forma que o corpo humano é um organismo exposto a vários tipos de perigos e riscos, manifestados principalmente na forma de doenças, e reage por meio de seu sistema imunológico, o Estado é um organismo que também tem que lidar com seus eventuais hospedeiros e tem um mecanismo de imunidade para secretá-los ou excretá-los (ESPOSITO, 2017). Daí a necropolítica, que parece estar ligada a essa lógica, produzindo a morte de certas populações ou setores sociais, entendidos como organismos ameaçadores à saúde do Estado.

Estamos acostumados com a ideia de que o neoliberalismo deixou o mundo com fome e marginalizou as redes de segurança social, os sistemas de saúde e educação e outras infraestruturas de apoio à vida humana. Ao mesmo tempo, porém, os regimes neoliberais em todas as escalas têm comprovadamente mimado e apoiado pacotes de capital, de várias formas diferentes, em uma extensão nunca sonhada pelos beneficiários humanos do bem-estar keynesiano nas décadas imediatas do pós-Segunda Guerra. Por meio da desregulamentação, brechas fiscais, abatimentos, perdões e pacotes de resgate maciços de empresas grandes demais para falir, esses regimes têm repetidamente promulgado programas extravagantes para 'fazer o capital viver' em vez de 'deixá-lo morrer', ao mesmo tempo em que medidas de proteção social, de 
renda mínima ou auxílio emergencial para os mais pobres e vulneráveis são questionados como assistencialistas, populistas e antagônicos ao capitalismo (SODRÉ, 2021). Não deixa as pessoas conseguirem por elas mesmas o sustento. Torna-as viciadas em políticas públicas. Esse é o argumento mais comum, conformista: "temos que ensinar a pescar e não dar o peixe". Ou não seria mais preciso: temos que deixar morrer de fome e não dar auxílio? Afinal, o Estado deve ser mínimo. Precisa. Viva as reformas. Mas mínimo para quem mesmo?

Esta edição da Revista Eletrônica de Comunicação, Informação \& Inovação em Saúde (Reciis) traz a segunda parte do dossiê Comunicação, saúde e crises globais, com a colaboração de Ravindra Kumar Vemula e Allan Santos como editores convidados. Os artigos que compõem o dossiê são variados: a cobertura sobre o isolamento social feita pelo jornal O Globo, a problemática das fake news durante a pandemia de Covid-19, o discurso antivacina no YouTube, a expansão do uso de aplicativos para controle da saúde mental e a cobertura sobre a Aids pelo jornal Correio de Notícias, de 1987 a 1992.

Entre os artigos publicados por meio da demanda de fluxo regular, temos um conjunto variado de textos sobre as relações entre comunicação, informação e saúde: a representação do câncer em histórias em quadrinho, o movimento de afirmação do corpo gordo no Instagram, as campanhas de saúde e a comunicação pública, as práticas educacionais em ambientes virtuais, e outros.

Coube à Ana Regina Rego ser a entrevistada desta edição. Numa entrevista dada à editora assistente Ana Carolina Monari, a professora aborda aspectos de seu livro A construção intencional da ignorância: o mercado das informações falsas, escrito em parceria com Marialva Barbosa. Reflete sobre os processos de desinformação durante a pandemia de Covid-19 e os abalos na democracia num regime de verdade baseado na pessoalidade e no populismo de extrema direita.

Em seu ensaio teórico, Maria Cristina Franco Ferraz recupera a obra de Heinrich von Kleist, poeta alemão que, no século XIX, refletira sobre o isolamento social. A leitura da autora é inspirada pela filosofia de Gilles Deleuze e Félix Gattari.

As notas de conjuntura analisam a pandemia de Covid-19 como infodemia e o uso de diferentes formas de gráficos de conhecimento para representar os dados sobre a Covid-19.

\section{REFERÊNCIAS}

AGAMBEN, Giorgio. Estado de exceção. São Paulo: Boitempo, 2004.

CAPONI, Sandra. Covid-19 no Brasil: entre o negacionismo e a razão neoliberal. Estudos Avançados, São Paulo, v. 34, n. 99, p. 209-224, 2020. DOI: https://doi.org/10.1590/s0103-4014.2020.3499.013. Disponível em: https://www.scielo.br/scielo.php?pid=S0103-40142020000200209\&script=sci arttext. Acesso em: 03 mar. 2021.

CORREA, Marilena Cordeiro Dias Villela; VILLARINHO, Luiz; BARROSO, Wanise Borges Gouvea. Controvérsias em torno do uso experimental da cloroquina/hidroxicloroquina contra a Covid-19: "no magic bullet". Physis: Revista de Saúde Coletiva, Rio de Janeiro, v. 30, n. 2, p. 1-21, 2020. DOI: https:// doi.org/10.1590/S0103-73312020300217. Disponível em: https://www.scielosp.org/article/physis/2020. v30n2/e300217/pt/. Acesso em: 03 mar. 2021.

ESPOSITO, Roberto. Termos da política: comunidade, imunidade, biopolítica. Curitiba: Editora da UFPR, 2017.

FOUCAULT, Michel. História da sexualidade: a vontade de saber. Rio de Janeiro: Graal, 1978. v. 1.

MBEMBE, Achile. Necropolítica. São Paulo: N-1, 2016.

SACRAMENTO, Igor. A melodramatização da pandemia: a Covid-19 e as dinâmicas de representação do inimigo. In: BARBOSA, Marialva; SACRAMENTO, Igor (org.). Vozes consoantes: comunicação e cultura em tempos de pandemia. Rio de Janeiro: Mauad X, 2020, p. 116-131. v. 1. 
Reciis - Revista Eletrônica de Comunicação, Informação \& Inovação em Saúde, Rio de Janeiro, v. 15, n. 1, p. 01-05, jan./mar. 2021 [www.reciis.icict.fiocruz.br] e-ISSN 1981-6278

SACRAMENTO, Igor; MONARI, Ana Carolina Pontalti; CHEN, Xuewu. O vírus do morcego: fake news e estereotiparem dos hábitos alimentares chineses no contexto da Covid-19. Comunicação \& Inovação, São Caetano do Sul, v. 21, n. 47, p. 82-98, 2020. Disponível em: https://seer.uscs.edu.br/index.php/ revista_comunicacao inovacao/article/view/7285. Acesso em: 03 mar. 2021.

SODRÉ, Muniz. A sociedade incivil: mídia, iliberalismo e finanças. Petrópolis: Vozes, 2021. 